\title{
Valley Forge Steel: Strategy, Risk and Reward? A Graduate Case in Strategy and Management Accounting
}

\author{
Patrick O’Meara
}

Patrick O’Meara (pomeara@niagara.edu) is an Assistant Professor of Accounting in the College of Business at Niagara University, 5795 Lewiston Road, Lewiston, NY, USA, 14109. This case was developed and used in ACC 335 (Cost Accounting) at Niagara University in the Spring semester of 2019. For access to the suggested answer key, please contact the author.

\section{Learning Outcome Statement (Abstract)}

At the completion of this case graduate learners should be able to demonstrate their knowledge of cost-volume-profit (CVP) analysis through the application of relevant case facts in determining a firm's fixed and variable costs. Learners should also be able to distinguish between sunk and marginal costs and operating and capital costs. In addition, learners should be able to develop a cash flow statement. Learners should be able to apply net present value and internal rates of return in making a recommendation to accept or reject a business proposal. Learners should also be able to demonstrate an understanding of the concepts of degree of leverage and margin of safety. In addition, learners should be 
able to apply Porter's Model of Competitive Strategy. This case is intended as a final graduate-level integrated case in the application of cost and managerial accounting concepts, and the application of Porter's Five Forces Model.

Keywords: Porter's Five Forces, Cost Structure, Net Present Value, Internal Rate of Return, Capital Budgeting, Degree of Leverage, Margin of Safety, Degree of Operating Leverage

DOI: https://dx.doi.org/10.15239/j.brcadvje.2020.04.04.ja06

\section{Economic Overview: Background to the Valley Forge CASE}

\section{The U.S. Economy}

In the summer of 2019, the Dow Jones Composite Stock Index closed at one of its all-time highs, $13,234.79^{1}$. The U.S. economy was on a roll with the U.S. unemployment rate at an all-time low of $3.7 \%^{2}$. Indeed, for the first half of 2019, U.S. GDP grew by $2.1 \%^{3}$. However, there are economic signals that point to the potential for recession in the near term.

\section{The Global Economy}

Indeed, despite all of the positive trends, there are some signs on the horizon which potentially do not bode well for the U.S. economy. Trade disputes between China and the United States have the potential to dispute global trade and commerce.

\section{The U.S. Treasury Yield}

In early August the U.S. government treasury yield "inverted". Inverted yield curves happen when short-term interest rates move higher than long-term interest rates. Normally, interest rates are higher for longterm investments, and lower for shorter term investments, in recognition that long-term investments have inherently higher risk. In August, the 3month and 2-year U.S. Government treasuries were yielding 1.999\% and 
$1.634 \%$ respectively. As noted by many economists, an inverted yieldcurve has a very strong correlation with a downturn in the economy, with future recessions occurring 18 to 24 months after the inversion. (Table 1).

\section{An Opportunity for Valley Forge Steel?}

Located in the Northeastern United States, Valley Forge Steel has survived many an economic downtown. Founded in the late 1970s, Valley Forge has historically focused on supplying steel to small and medium sized manufacturing companies and builders across the northeastern and great lakes areas of the United States.

Its current production processes are based on a production line which was built in the 1970s, and has only been marginally updated over the years. This line currently produces approximately 40,000 metric tonnes (m.t.) of steel annually. Valley Forge's management is considering renovating some existing space at its manufacturing facilities to make way for a second production line that would produce an additional 63,000 m.t. of product that could be sold into two new market areas - the Southern and Midwestern United States.

The new production line would be able to produce more steel due to the use of computer automation which produces a better-quality product in less production time. The new production line has the potential to open-up new markets for Valley Forge, given a research report completed by Market Way Research in 2018. The extensive report, costing $\$ 100,000$, identified the southern and mid-western states as having greater economic potential given higher economic growth in these regions over the past five years.

The new production line would cost $\$ 2,000,000$. In addition, installation of the new blast furnace would require electrical work costing $\$ 100,000$, as well as, $\$ 150,000$ in additional building renovations. Despite $\$ 180,000$ in repairs that were completed last year, the city council is requiring these further updates to Valley Forge's building to ensure that it meets 
the newly passed state building safety code. As a result of all of these renovations, management is projecting a $\$ 5,000$ increase in annual property taxes in the second year of the new line's life. Valley Forge currently pays $\$ 25,000$ annually in property taxes. The cost of the new production line will be depreciated over five years with no salvage value.

To support the new production line, two new long-haul trucks will need to be purchased at a cost of $\$ 125,000$ each. Each new truck is estimated to have annual operating costs of $\$ 25,000$. The trucks are expected to have no salvage value at the end of their useful life, and will be depreciated over five years.

Currently, Valley Forge burns through approximately $\$ 150,000$ in working capital annually. Management is predicting that the new line would require an additional $\$ 200,000$ in working capital and a large compliment of new staff.

The new line would require the addition of new management, and supervisory staff, as well as, more production employees and a new mechanical engineer to take over the role of Mike Mechanisky, who recently retired. The new engineer will report to the Vice President of Production and will be paid $\$ 125,000$ in salary, plus $20 \%$ benefits.

In addition to the three existing managers that work the original production line, two new production managers and a night production supervisor will need to be hired. Production managers are normally paid $\$ 80,000$ annually, plus a benefits premium of $20 \%$. Night supervisors are paid $\$ 58,000$ annually, plus a $20 \%$ benefits premium (Table 2 ).

Hourly production staff are paid $\$ 22$ per hour when they are assigned shifts one or two (day shifts) and receive a $\$ 1.00$ per hour shift premium if they are assigned shift three - the night shift. In addition, all production staff receive group health, dental and pension benefits equal to $15 \%$ of what they are paid on an hourly basis.

The new combined management team will report to the Vice President of Production. This includes the three current production managers, all 
new managers, and the plant's accountant. The plant's bookkeeper will continue to report directly to the plant accountant. The new night shift supervisor will report to the shift one manager of the new production line (Table 3 and 4).

The increased management workload for the Vice President of Production will result in a $\$ 50,000$ salary increase effective immediately.

\section{An Overview of Steel Production}

Steel is produced using iron ore that is mined from the ground. The iron is then smelted in large blast furnaces where impurities are removed and carbon dioxide is added. Carbon dioxide is added to steel to give the metal is durability and hardness. In general, steel is made of three component ingredients: coking coal, limestone, and iron one. To produce one metric ton (m.t.) of steel, 2 m.t. of iron ore, 1 m.t. of coking coal and a half m.t. of limestone are required ${ }^{4}$ (Table 5).

\section{Preview Complete}

This concludes the free, limited preview of this paper. Please buy full access.

\section{Citation Information}

Patrick O’Meara, Patrick O.“Valley Forge Steel: Strategy, Risk and Reward? A Graduate Case in Strategy and Management Accounting." BRC Fournal of Advances in Education 4, no. 1 (2020):87-95. https://dx.doi.org/10.15239/ j.brcadvje.2020.04.01.ja06 
48 BRC Journal of Advances in Education Vol. 4, No. 1

\section{WeB APPE NDIX}

A web appendix for this case is available at: https://dx.doi.org/10.15239/ j.brcadvje.2020.04.01.wa06 


\section{Notes}

1. www.yahoo.com (July 8, 2019)

2. (http://www.ncsl.org/research/labor-and-employment/nationalemployment-monthly-update.aspx)

3. https://tradingeconomics.com/united-states/gdp-growth)

4. www.howstuffworks.com) (July8, 2019) 